American Journal of Applied Sciences 5 (8): 959-962, 2008

ISSN 1546-9239

(C) 2008 Science Publications

\title{
Continuous Production of Lime Juice by Vacuum Freeze Drying
}

\author{
Wasan Theansuwan, Kitichai Triratanasirichai and Kiatfa Tangchaichit \\ Department of Mechanical Engineering, Khon Kaen University, 123 Mittraparb Road, \\ Muang District, Khon Kaen 40002, Thailand
}

\begin{abstract}
An experimental dryer was developed to determine the characteristics of lime juice powder that produced from freeze-drying processes on continuous production. The experimental process consists of two processes, freezing process (the air blast freezer type) and freeze-drying process (tray method with heating plate type). $\mathrm{NaHCO}_{3}(2 \%$ by weight of lime juice) was dissolved in lime juice as solid aid. The result was found that this experimental dryer can produce lime juice powder which has the similar properties to lime juice. Combining two processes, freezing process and freeze-drying process, the experimental dryer on continuous production can efficiently achieve the sensible result.
\end{abstract}

Key words: Vacuum freeze drying, air blast freezing

\section{INTRODUCTION}

Lime (Citrus aurantifolia) is an important agricultural product in Thailand. Lime has been used to prevent scurvy, a disease caused by a deficiency of vitamin C. Traditionally, lime has been used as a remedy for indigestion, heartburn and nausea. It also has cooling effects on fevers and can help ease coughs and various respiratory disorders ${ }^{[3,7]}$. The preservation or modification techniques of lime during seasoning are necessary in order to preserve lime for off season, apply for other purposes and also to control the price of lime. In this study, the vacuum freeze dryer technique is designed to produce lime juice powder in order to preserve lime products.

Vacuum freeze-drying is one of the best methods for drying and producing final products of highest quality as comparing to other drying technologies. Besides, as the moisture content of products is reduced, the process temperature is decreased and most of the deterioration and microbiological reactions are also ended. Therefore, both preservation and value-add of high-value food are achieved by using this technology ${ }^{[9,10]}$. The vacuum freeze-drying consists of two important systems; freezing system and freeze drying system. Freezing required the removal of heat. Ideally, two-component liquid systems, water and solute, are crystallized ${ }^{[6]}$. In order to have freezing operations to be cost-effective, it is necessary to optimally design the efficient refrigeration system. Such a system includes compressor, condenser, evaporator and axial $\operatorname{fan}^{[1,2,4,6,8]}$. The other part of the system, the freeze drying must remove water of product by sublimation process and also involves mass and heat transfer ${ }^{[8]}$. Thus, the refrigeration system must work for both processes appropriately.

Freeze-dried lime juice powder process begins with freezing the product (lime juice) in the freezer and then continues to the freeze-dryer for the freeze-drying process $^{[7]}$. As a result, the vacuum freeze dryer can satisfactorily work both freezing process and drying process on continuous production of producing lime juice powder.

\section{MATERIALS AND METHODS}

Sample preparation: Lime (Citrus aurantifolia) was purchased from a local market in Khon Kaen, Thailand. The average amount of lime juice per one kilogram of lime is $582.6 \mathrm{~mL}$ or $0.5532 \mathrm{~kg}$. The $\mathrm{NaHCO}_{3}$ was purchased from Sahawitthayasom Co.,Ltd, Khon Kaen, Thailand.

Experimental apparatus preparation: Figure 1 illustrates the schematic diagram of freeze dryer, which was designed by researcher. Briefly, it consists of refrigeration system, cooling fan, freezing chamber and measurement instruments. The rectangular trays were made from $0.8 \mathrm{~mm}$-stainless steel thick. The trays were divided into 8 blocks. Each tray had a small hole at the bottom of the block to allow lime juice to flow from one block to the other. The cooling unit was designed to be $3.75 \mathrm{~kW}$ of cooling capacity using R-22 refrigerant. The fin spacing of the evaporator is $10 \mathrm{~mm}$ and area

Corresponding Author: Wasan Theansuwan, Department of Mechanical Engineering, Khon Kaen University, 123 Mittraparb Road, Muang District, Khon Kaen 40002, Thailand 


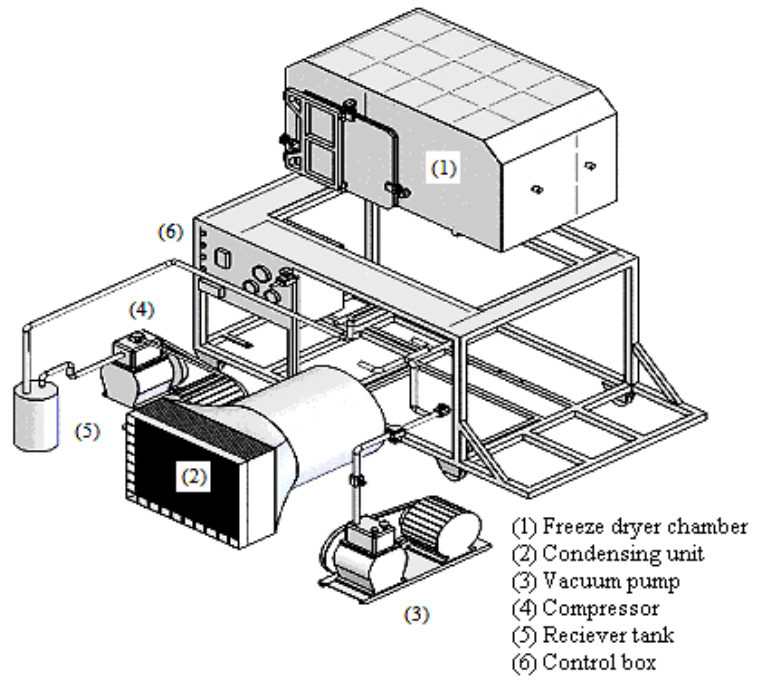

Fig. 1: The assembly of freeze dryer

surface is $10 \mathrm{~m}^{2}$. The mechanical devices in the freeze drying chamber were used to control the direction of air flow into each tray in order to equalize the velocity. The wall was covered with $0.005 \mathrm{~m}$ polystyrene sheets to improve thermal insulation. Two thermocouple (type-T) wires were immersed in the lime juice in each tray. They were placed $133.33 \mathrm{~mm}$. apart at the middle of the tray. The speed of the cooling fan was controlled via an inverter (T-VERTER 2N-Series-220*1.5kW; Model N2-202-M).The vacuum pressure in freeze drying chamber was adjust by vacuum pump (OP model CVD-3: 300 liters $/ \mathrm{min}, 5 \times 10^{-4}$ torr). The heating units, 4 sets of $2,000 \mathrm{~W}-220 \mathrm{~V}$ single phase heating plate of $38 \times 50 \mathrm{~cm}$ and $0.5 \mathrm{~cm}$ thickness were controlled by microcontroller (developed by researcher). The electrical signals of the samples were collected by a data logger (YOKOGAWA; Model DAQSTATION DX200) and the data were stored on a floppy disk.

Experimental method: The fresh lime was used in the experiment. Lime was washed, cut into two pieces and squeezed to get lime juice (60 units/1 liters of juice) using a stainless steel juice squeezer. The $\mathrm{NaHCO}_{3}(2 \%$ by weight of lime juice) was dissolved in lime juice solution $^{[7]}$. The sample solution was poured into six trays and placed on three shelves in the freezing chamber. Lime juice was frozen as layer with the experimental thickness of 4, 6, 8 and $10 \mathrm{~mm}$. Inside the chamber, there was a cooling fan that used for circulating the freezing air while the freezing process was taken place. Freezing process started with an initial temperature of $20 \pm 1^{\circ} \mathrm{C}$ and continued until final temperature of $-20 \pm 1^{\circ} \mathrm{C}$. The freeze drying process began with shutting off the cooling fan then starting the

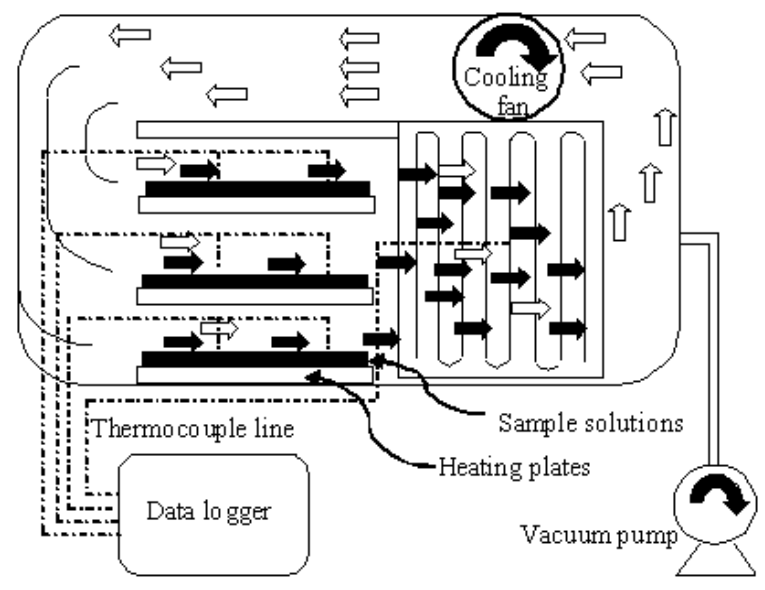

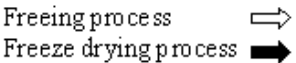

Fig. 2: The schematic diagram of continuous production of lime juice by vacuum freeze drying

vacuum pump Fig. 2. When the vacuum pump reached the steady state, the heating plate was turned on. Freeze drying process started with an initial temperature of $20 \pm 1^{\circ} \mathrm{C}$ and continued until final temperature of $40 \pm 1^{\circ} \mathrm{C}$.

\section{RESULTS AND DISCUSSION}

Figure 3 shows the sublimation cycle found in system utilizing vacuum freeze-dryer. After tuning on the cooling fan, the temperature of the sample solutions were dropped to $-20^{\circ} \mathrm{C}$ and the temperature of the coldtrap was dropped to a little lower than $-20^{\circ} \mathrm{C}$. Then shutting off the cooling fan and starting the vacuum pump, the temperature of the cold-trap was dropped to about $-40^{\circ} \mathrm{C}$. The molecule of the water of the sample solutions started to sublimate and condense at the coldtrap. While the heating plate was giving out the heat, the temperature of the sample solutions got higher. Then the temperature between the cold trap and the sample solutions got more different, the sublimation rate got higher until the sample solutions reached the final temperature of $40^{\circ} \mathrm{C}$ and the temperature was steady for about 30 minutes. The results show that the ratio between the whole process and layer thickness of lime juice at 4, 6, 8 and $10 \mathrm{~mm}$ are 273.0, 201.3, 168.0 and $149.0 \mathrm{~min} / \mathrm{mm}$, respectively.

The results were compared between fresh lime juice and lime juice powder at different layer thicknesses of lime juice. After testing the properties of the product results (lime juice powder), Vitamin C 
Am. J. Applied Sci., 5 (8): 959-962, 2008

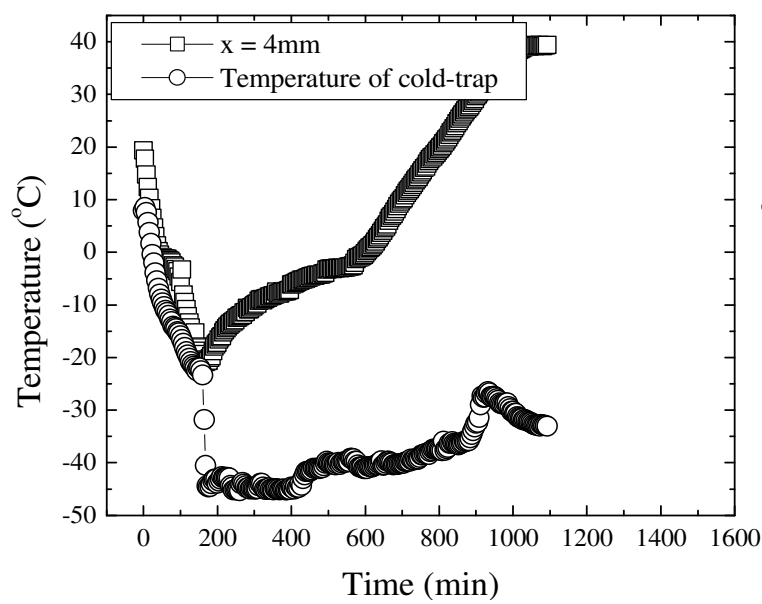

(a)

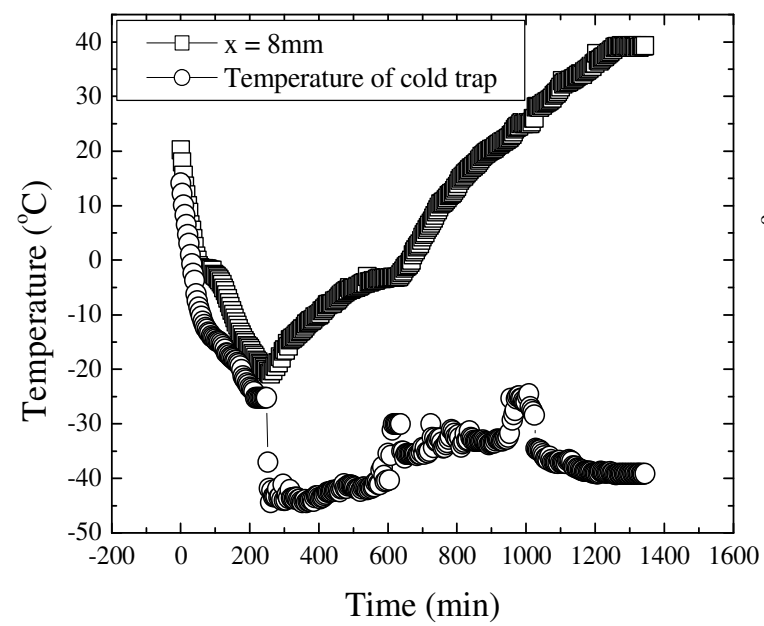

(c)

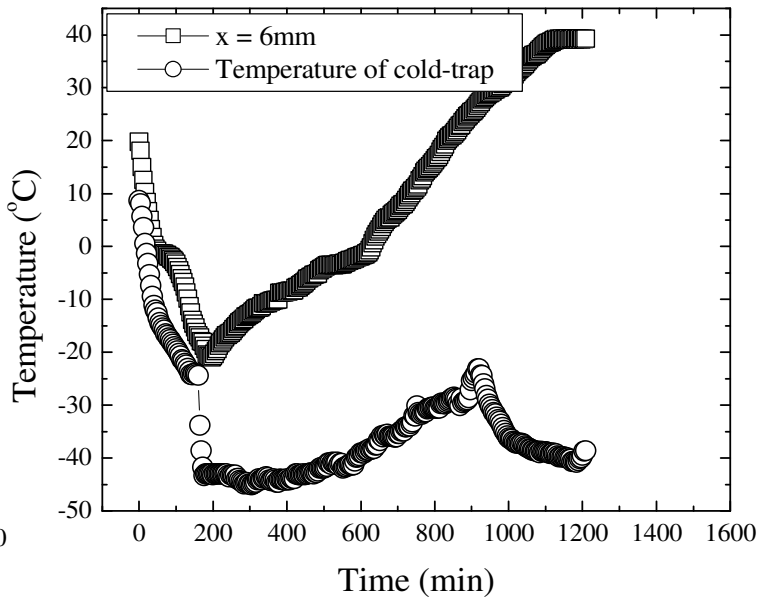

(b)

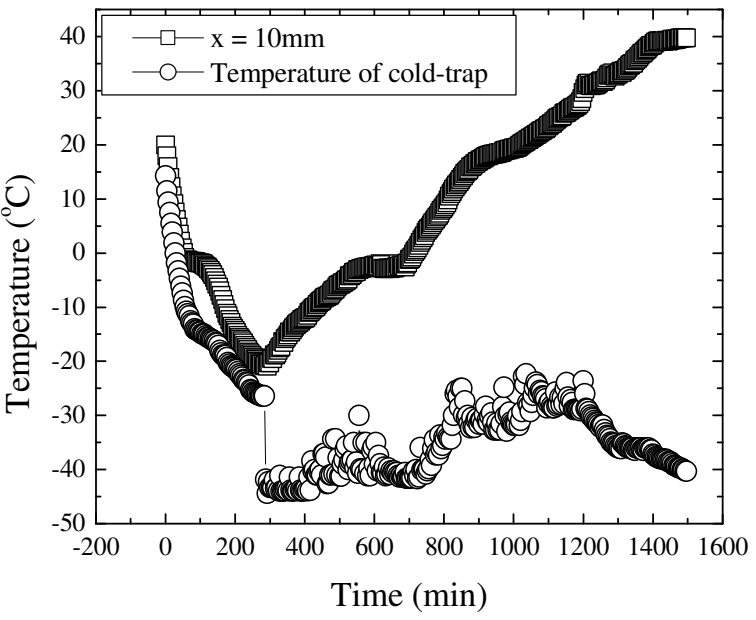

(d)

Fig. 3: The sublimation cycle found in system utilizing vacuum freeze-dryer. (a) $x=4 \mathrm{~mm}$, (b) $x=6 \mathrm{~mm}$, (c) $x=8$ $\mathrm{mm}$ and (d) $x=10 \mathrm{~mm}$

Table 1: The comparison of analyze qualitatively between lime juice and lime powder

\begin{tabular}{|c|c|c|c|c|}
\hline \multirow[b]{2}{*}{ Description } & \multicolumn{2}{|c|}{ Result (Lime) } & \multirow[b]{2}{*}{ Unit } & \multirow[b]{2}{*}{ Method } \\
\hline & Juice & Powder & & \\
\hline \multicolumn{5}{|l|}{ Chemical } \\
\hline Vitamin C & 330.2 & 282.9 & mg/100g (by dry weight) & HPCL \\
\hline Citric Acid & 28.14 & 13.41 & $\%(10 \%$ solution $)$ & AOAC (2000) \\
\hline $\mathrm{pH}$ & 2.45 & 3.66 & $\mathrm{pH}$-range & AOAC (2000) \\
\hline Moisture Content & 92.22 & 3.69 & $\mathrm{~g} / 100 \mathrm{~g}$ & AOAC (2000) \\
\hline Water Activity & 0.99 & 0.35 & & AOAC (2000) \\
\hline \multicolumn{5}{|l|}{ Physical* } \\
\hline Color & 3 & 3.6 & score & TIS 537/2547 (2003) \\
\hline Taste & 3 & 3 & score & TIS 537/2547 (2003) \\
\hline Dissolution & - & 3.2 & score & TIS 537/2547 (2003) \\
\hline General & 3 & 3.2 & score & TIS 537/2547 (2003) \\
\hline
\end{tabular}

*The score of physical analysis on standard is $\geq 3$. 
Am. J. Applied Sci., 5 (8): 959-962, 2008

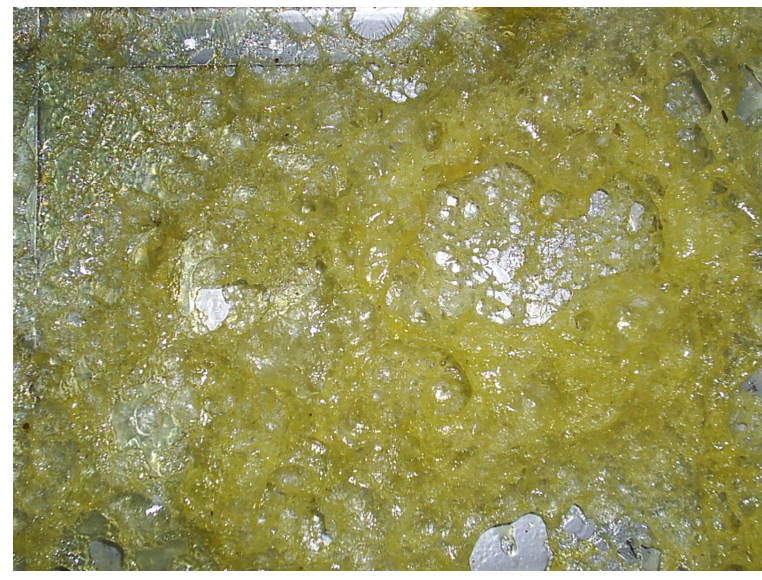

Fig. 4: The photograph of final product (Lime powder) from continuous production by vacuum freeze drying, which is contained in the trays

reduced about $14.3 \%$, Citric acid reduced $52.35 \%, \mathrm{pH}$ increased about $49.3 \%$, moisture content reduced to $3.96 \mathrm{~g} / 100 \mathrm{~g}$ and water activity reduced to 0.35 . All physical properties results were passed standard. The comparison of fresh lime juice and lime juice powder properties is shown in Table 1.

The result was Certificated by Laboratory Center for Food and Agricultural Products Co.,Ltd.: LCFABranch: Nai Muang, Khonkaen, Thailand.

Figure 4 shows the final Product (Lime powder), which is the product from continuous production by vacuum freeze drying. The product is a brittle sheet in bright yellow color.

\section{CONCLUSION}

The developed vacuum freeze drying via both freezing and drying processes can be used in continuous production. The most advantage of this machine is it can be utilized both freezing and drying processes. Moreover, the designed evaporator in the refrigeration system that used in this machine can also work in two different purposes. It can be used in a cooling step in the freezing process and also can be used in a coldtrapping step in the freezing drying process. Thus, the developed machine can continuously produce lime juice powder. With this machine, the production cost could be reduced and the produced lime juice powder also has the similar properties as lime juice. The machine could be developed for other types of freeze drying industries such as medicine and food.

\section{ACKNOWLEDGEMENT}

This research is financially supported by Commission On Higher Education, Ministry of Education, Thailand.

\section{REFERENCES}

1. AI-Otaibi, A.D., I. Dincer and M. Kalyon, 2004. Thermoeconomic optimization of vaporcompression Refrigeration systems. Int. Comm. Heat Mass Transfer, 31(1): 95-107.

2. Aprea, C. and A. Greco, 2003. Performance evaluation of $\mathrm{R} 22$ and $\mathrm{R} 407 \mathrm{C}$ in a vapour compression plant with reciprocating compressor. Applied Thermal Eng., 23: 215-227.

3. Morton, F.J., 1987. In Fruits of Warm Climates, 160-168, Creative Resource Systems, Inc., Winterville, N.C.

4. Khan, J. and M.S. Zubair, 1990. Design and performance evaluation of reciprocating refrigeration systems. Int. J. Refrigeration, 22: 235-243.

5. Becker, R.B. and A.B. Fricke, 2004. Heat transfer coefficients for forced-air cooling and freezing of selected foods. Int. J. Refrigeration, 27: 540-551.

6. Becker, R.B. and A.B. Fricke, 1999. Freezing times of regularly shaped food items. Int. Comm. Heat Mass Transfer, 26 (5): 617-626.

7. Chaisawadi, S., W. Methawiriyasilp, D. Thongbute and T. Chayawattana, 2005. Clean Production of Commercial Freeze-dried Lime Powder for Medicinal Herb and Nutritional Health Benefits. Acta Hort., (ISHS) 679: 29-35.

8. Sanaye, S. and H.R. Malekmohammadi, 2004. Thermal and Economical optimization of air conditioning units with vapor compression refrigeration system, Applied Thermal Eng. 24: 1807-1825.

9. Toledo, T.R., 1999. Fundamentals of Food Process Engineering 2nd Edn., Gaithersburg, Mari yard.

10. Chen, W., B.K.L. Gast and S. Smithey, 2000. The effects of different freeze-drying processes on the moisture content, color and physical strength of roses and carnations, Scientia Horti., 84: 321-332. 